\title{
Impaired physical mobility in chronic kidney disease: nursing diagnosis
}

\begin{abstract}
Symptoms such as weakness and fatigue are common in the population of chronic kidney patients, in consequence of a combination of multiple factors, including hormonal imbalance, impaired nutrition and inadequate transport of $\mathrm{O}_{2}$, as a consequence of anemia, uremia, and sarcopenia. The last one results in the reduction of mass, strength and muscle functioning. Also, with increasing age, physical limitations of chronic kidney patients on hemodialysis tend to progress, reducing flexibility, agility, mobility in joints and balance. Impaired mobility in a functional perspective is seen as the inability of the individual to move freely. The nursing diagnosis "Impaired physical mobility" suggests changes in gait running, which causes the increased risk for falls and dependence related to everyday activities. Thus, it is crucial to reflect the real state of the patient to early pursue an accurate Nursing Diagnosis that best reflects the patient's needs.
\end{abstract}

Keywords: renal insufficiency, chronic, mobility limitation, nursing diagnosis
Volume 3 Issue 3 - 2017

\author{
Olvani Martins da Silva \\ Department of Nursing, University the Estado de Santa \\ Catarina, Brazil
}

\begin{abstract}
Correspondence: Olvani Martins da Silva, Department of Nursing, University the Estado de Santa Catarina, Brazil, Tel 5149 2049 9580,Email olvanims@hotmail.com
\end{abstract}

Received: May 21, 2017 | Published: July 17, 2017

\section{Abbreviations: $\mathrm{O}_{2}$, oxygen}

\section{Introduction}

Chronic kidney disease along with hemodialysis treatment alters people's lifestyles. Symptoms of weakness and fatigue are commonly reported by patients, as a result of various mechanisms contributing to this process. Among them are hormonal imbalance, impaired nutrition and inadequate transport of $\mathrm{O}_{2}$, in consequence of anemia. ${ }^{1}$ A cohort study, performed with chronic renal patients in stage three and four, with no previous account of anemia, evaluated the relationships of aerobic exercise performance, muscle strength and fatigue with renal function and muscle mass, by using ergometric tests and leg strength tests, Cycle Ergometer and Oxygen Peak Consumption. Only nine patients completed the two-year segment of the study. The results showed reduced exercise performance in stages three and four of CKD, even in the absence of anemia and, exercise performance decreased progressively as renal function deteriorated. ${ }^{2}$

It is believed that besides the mechanisms mentioned, other factors that contribute to exercise performance may be related to electrolytic disturbance, metabolic acidosis, loss of muscle mass and atrophy of muscle fibers. ${ }^{1,3}$ The loss of muscle mass, strength reduction and muscle function is a serious indicator in kidney disease, as it characterizes the sarcopenia state, which along with uremia determines a progressive condition in renal disease. The more advanced the stage of the disease is, the greater the functional impairment presented by the patient due to the presence of sarcopenia is. ${ }^{1}$

Moreover, physical activity, in general, decreases in patients having dialysis, and reduced activity or sedentary lifestyle is associated with lower levels of serum albumin and creatinine that show protein energy loss and small skeletal muscle mass. ${ }^{4}$ Thus, physical limitations tend to progress with patient's advancing age, reducing flexibility, agility, mobility in joints and balance, which is the ability to remain erect and firm when inert or wandering. ${ }^{5}$

The loss of balance, along with impaired mobility is a predisposing factor to the risk of falls, which in turn can cause from minor injuries to limitations in everyday life, ${ }^{6}$ such as, going up and down stairs due to impairment of the locomotor and neurological system. ${ }^{7}$ In a moderate phase, there is loss of functional autonomy, and in more severe situations, there are fractures, which may even be fatal. ${ }^{6}$

Impaired mobility in a functional perspective is seen as the individual's inability to move freely, this occurs in a varied way for each individual, or even in the same individual, this incapacity may be present in different degrees with periods when the symptoms are mild and also periods when physical limitations are more severe. ${ }^{8}$

A Brazilian study that used the SF-36 Generic Quality of Life Questionnaire to evaluate the quality of life of 28 chronic renal patients having hemodialysis, found that from the eight domains observed by the instrument, the Limitation by physical aspects presented a score with a mean of $12.5 \%$, (where 0 represents the worst score and 100 the best health status score). Greater difficulty of activities was related to vigorous activities, such as running, lifting heavy objects and taking part in strenuous sports. Greater limitations were observed in vigorous activities, such as climbing several flights of stairs or running several blocks, proving that the greater the degree of effort and complexity is, the greater the difficulties presented are. ${ }^{9}$

Although limitation of physical mobility may occur suddenly or slowly, it may be a predisposing factor of a series of health complications. ${ }^{8}$ Taking it into consideration, the hemodialysis nurse has the responsibility of identifying the needs of patients who are vulnerable to this condition, through the nursing diagnosis, and to be able to clearly identify the diagnosis of impaired physical mobility, in order to promote interventions, directing care effectively.

The nursing diagnosis "Impaired physical mobility" suggests changes in gait running, which causes increased risk for falls and dependence regarding everyday activities. ${ }^{8}$ It may have lack of physical conditioning, reduction of muscle strength and mass, activity intolerance, musculoskeletal and neuromuscular impairment as related factors. ${ }^{10}$ 
However, the interpretation of the diagnoses may vary according to nurse's understanding of the patient's responses and health problems. Thus, it is essential to reflect the patient's actual state, to seek an accurate nursing diagnosis for the evaluator's judgment in relation to the degree of relevance, specificity and consistency of the existing clues for an early diagnosis elaboration that best reflects the patient's needs. ${ }^{10}$

\section{Conclusion}

With increasing age, physical limitations of chronic kidney patients on hemodialysis tend to progress, reducing flexibility, agility, mobility in joints and balance. Thus, it is crucial to reflect the real state of the patient to early pursue an accurate Nursing Diagnosis that best reflects the patient's needs.

\section{Acknowledgements}

None.

\section{Conflict of interest}

The author declares no conflict of interest.

\section{References}

1. Souza VA, Oliveira D, Mansur HN, et al. Sarcopenia na doença renal crônica. J Bras Nefrol. 2015;7(1):98-105.

2. Leikis MJ, McKenna MJ, Petersen AC, et al. Exercise performance falls over time in patients with chronic kidney disease despite maintenance of hemoglobin concentration. Clin J Am Soc Nephrol. 2006;1(3):488-495.
3. Fahal IH. Uraemic sarcopenia: aetiology and implications. Nephrol Dial Transplant. 2014;29(9):1655-1665.

4. Greco A, Paroni G, Seripa D, et al. Frailty, disability and physical exercise in the aging process and in chronic kidney disease. Kidney Blood Press Res. 2014;39(2-3):164-168.

5. Nascimento LCG, Patrizzi LJ, Oliveira CCES. Result of four weeks of propreoceptive training in the studied postural balance of elderly. Fisioter Mov. 2012;25(2):325-331.

6. Dias BB, Mota RS, Gênova TC, et al. Aplicação da Escala de Equilíbrio de Berg para verificação do equilíbrio de idosos em diferentes fases do envelhecimento. RBCEH. 2009;6(2):213-224.

7. Mello PMS de. Tradução, adaptação cultural e validação de uma escala para aferir limitação da atividade de subir e descer escadas. Rev bras geriatr gerontol. 2013;16(3):433-441.

8. Costa AGS, Ana Railka de SO, Felipe Emmanuel CA, et al. Diagnóstico de enfermagem: mobilidade física prejudicada em pacientes acometidos por acidente vascular encefálico. Rev Esc Enferm USP. 2010;44(3):753758.

9. Silva OM, Olivvera F, Ascari RA, et al. The quality of life of the patient suffering from chronic renal insufficiency undergoing hemodialisys. $J$ Nurs UFPE on line. 2012;6(10):2777-2784.

10. Herrdman TH. Kamitsuru S Nursing Diagnoses the NANDA: Definition e Classification 2015/2017 Artemed. Porto Alegre: Springer; 2015. 